in the late $20^{\text {th }}$ century. However, as a "snapshot" of the then current vegetation, it can be criticized for lacking a sufficiently long-term perspective. Paleodata from South Wales and Northern England show the former presence of plant species regionally extinct as a result of human activity, including Sphagnum austinii (syn. S. imbricatum ssp. austinii) (McClymont et al., 2008, 2009), which was also a major peat former in raised bogs in England and Wales for thousands of years in the midlate Holocene (Hughes et al., 2007, 2008). Regional paleodata therefore imply that inter-regional translocation of key bog species could be justified as part of future habitat restoration. Moreover, paleoecological data of former plant communities show a wider range of possible restoration targets for Molinietum than is implied by the NVC, and so broaden the range of possible replacements. They also question the longevity of some Callunetum: its endurance in some parts of England and Wales has been shorter than generally thought (Fig. 2B; see also Chambers et al., 2007b).

Davies and Bunting (2010) argue there is an urgent need to "bridge the gap" between ecology and paleoecology. The latter has fundamental implications for the future practice of conservation and habitat management: regional paleoecological data question vegetation endurance, reveal regional declines, extinctions and their causes, and can help identify a range of viable restoration targets.

\section{References}

Chambers, F.M., Mauquoy, D. and Todd, P.A., 1999: Recent rise to dominance of Molinia caerulea in Environmentally Sensitive Areas: new perspectives from palaeoecological data, Journal of Applied Ecology, 26: 719-733.

Chambers, F.M., Mauquoy, D., Cloutman, E.W., Daniell, J.R.G. and. Jones, P.S., 2007a: Recent vegetation history of Drygarn Fawr (Elenydd SSSI), Cambrian Mountains, Wales: implications for conservation management of degraded blanket mires, Biodiversity and Conservation, 16: 2821-2846.

Davies, A.L. and Bunting, M.J., 2010: Applications of palaeoecology in conservation, The Open Ecology Journal, 3: 54-67.

McClymont, E.L., Mauquoy, D., Yeloff, D., Broekens, P., van Geel, B., Charman, D.J., Pancost, R.D., Chambers, F.M. and Evershed, R.P., 2008 The disappearance of Sphagnum imbricatum from Butterburn Flow, UK, The Holocene, 18: 991-1002.

Willis, K.J. and Birks, H.J.B., 2006: What is natural? The need for a longterm perspective in biodiversity conservation, Science, 314 1261-1265.

For full references please consult:

http://www.pages-igbp.org/products/newsletters/ref2011_2.pdf

\title{
Spatial and temporal controls on hydro-geomorphic processes in the French Prealps
}

\section{Darren S. Crook ${ }^{1}$, R.C. Chiverrell ${ }^{2}$, J.A. Dearing ${ }^{3}$, R.T. Jones ${ }^{4}$ and K.E. Welsh ${ }^{5}$}

'Division of Geography and Environmental Sciences, University of Hertfordshire, Hatfield, UK; D.Crook@herts.ac.uk ${ }^{2}$ Department of Geography, University of Liverpool, UK; ${ }^{3}$ Palaeoecology Laboratory, University of Southampton, UK; ${ }^{4}$ College of Life and Environmental Sciences, University of Exeter, UK; ${ }^{5}$ Department of Geography and Development Studies, University of Chester, UK

\section{Integration of paleoenvironmental reconstructions, environmental history and cellular modeling sheds light on the likely impacts of climate change on hydrological and geomorphological processes in the French Prealps.}

By the end of the $21^{\text {st }}$ century, IPCC reports (2007) suggest winter precipitation in European Alpine regions will increase by 10-20\% compared with 1980-1999, while summer precipitation will decrease by approximately $20 \%$. Here, we review findings

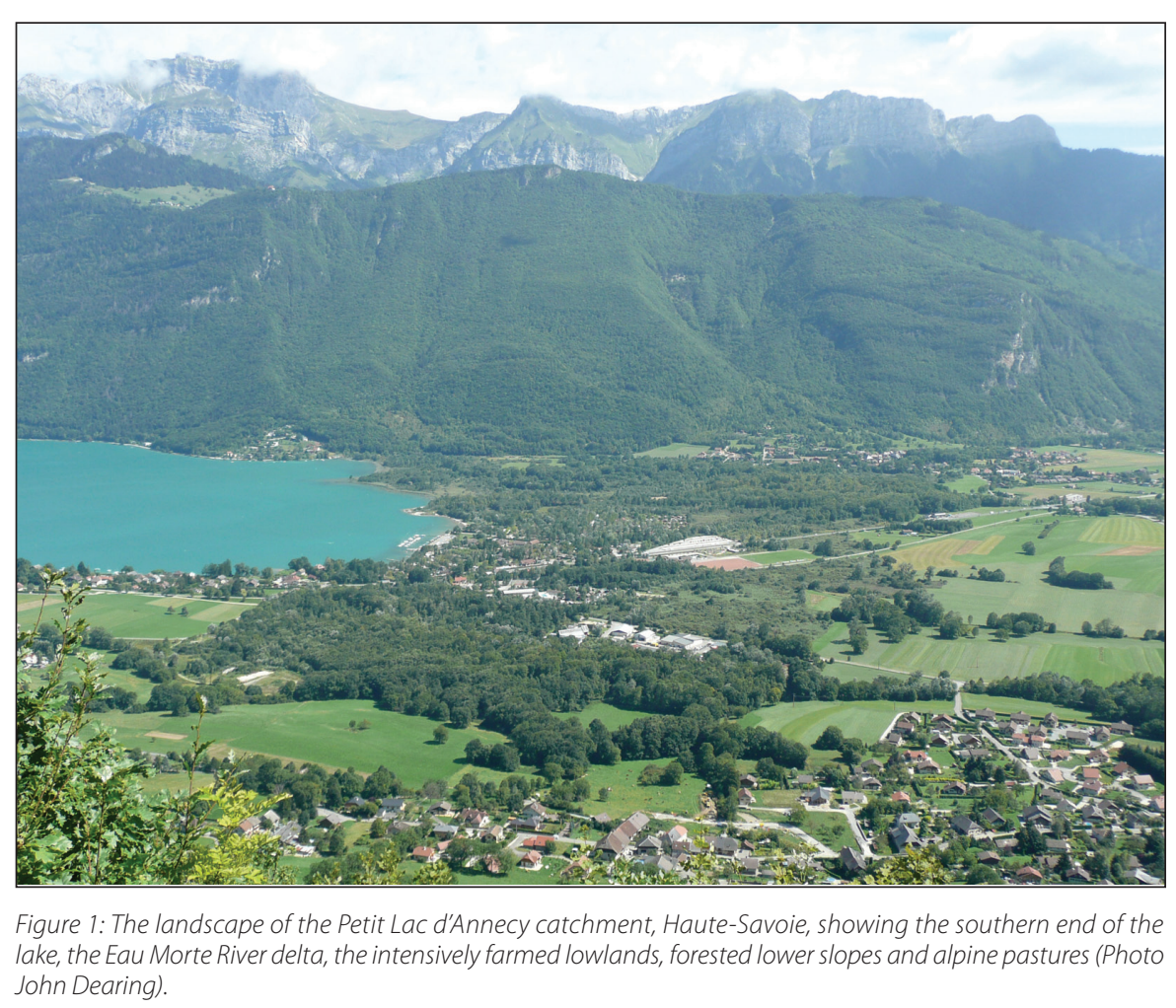

Figure 1: The landscape of the Petit Lac d'Annecy catchment, Haute-Savoie, showing the southern end of the lake, the Eau Morte River delta, the intensively farmed lowlands, forested lower slopes and alpine pastures (Photo John Dearing).

from research undertaken in the French Prealps in order to shed light on the implications of climate change for hydro-geomorphic processes. Over the past 20 years, the Annecy lake-catchment $\left(45^{\circ} 48^{\prime} \mathrm{N}\right.$, $\left.6^{\circ} 8^{\prime} \mathrm{E}\right)$ has provided the focus for a num- ber of studies, drawing on methods used in paleoecology, environmental history and process modeling, to investigate the links between human activities, climate and hydro-geomorphic processes. Lying at an altitude of $447 \mathrm{~m}$ asl in the prealps of Haute-Savoie, the lake comprises two basins, the Grand and Petit Lacs. Integration of data and models from mainly the Petit Lac and its catchment (Fig. 1) has generated significant insight into the spatiotemporal nature of human-environment interactions across the wider region.

\section{Paleoenvironmental reconstruction}

Foster et al. (2003) reconstructed the mechanisms of flooding and sediment transport within the Petit Lac catchment over timescales of months to centuries from lake and floodplain sediments that were representative of large catchment areas. Analysis of the results revealed that climate and land-use controls on the hydrological and sediment system were complex and varied according to the timescale of observation. In general, cycles of agricultural expansion and deforestation appeared to have been the major cause of shifts in the hydro-geomorphic system during the late Holocene. It was suggest- 
ed that deforestation might have caused a number of high-magnitude flood and erosion events. The authors also argued that as the timescale of observation becomes shorter (annual rather than centennial), the impact of climate or meteorological events on hydro-geomorphic processes become progressively more important, The authors showed that since the mid$19^{\text {th }}$ century, smoothed records of discharge roughly followed annual precipitation (Foster et al., 2003) whilst annual sediment load declined in parallel with the trend of declining land use pressure (Fig. 2). Episodic erosion events since the mid-19 ${ }^{\text {th }}$ century were linked to geomorphic evidence for slope instability in the montane and subalpine zones, triggered by intense summer rainfall (cf., Theler et al., 2010). At the annual scale, changes in seasonal rainfall become paramount in determining sediment movement to downstream locations. A recent rise in sediment yield, since the 1980s, points to a shift in seasonal rainfall patterns, which is also visible in the instrumental record (Fig. 2C).

\section{Environmental History}

Crook et al. $(2002$, 2004) investigated the nature of human impact on forest cover in the Petit Lac catchment and its link to flooding using local documentary sources for land use, flooding and climate. In contrast to the sediment studies, they identified the main period of large-scale, uniform and rapid deforestation in the catchment as the early $19^{\text {th }}$ century (Crook et al., 2002). It was a time of demographic expansion, industrial development, foreign occupation, war, caveats and laws, linked with local, endogenous pressures of land fragmentation, agricultural crisis, and the desire for new alpine pasture. However, coincident phases of deforestation and flooding (Fig. 2) were more evident in individual second order tributaries, such as the river Ire, than the whole catchment. Overall there were no obvious or simple causal links between forest cover change, climate anomalies and destructive flood events at the whole catchment scale in either the $18^{\text {th }}$ or $19^{\text {th }}$ century.

In a subsequent study, Crook et al., (2004), used archeological and documentary records to reconstruct land-use patterns and nutrient balance in Montmin, an upland commune, at even finer scales for specific periods in time between $A D$ 1561 and 1892. Previous studies by Siddle $(1986,1997)$ and Jones (1987) gave insight into the social fabric of the commune and the land use practices. Together, the results demonstrated that during this pe-

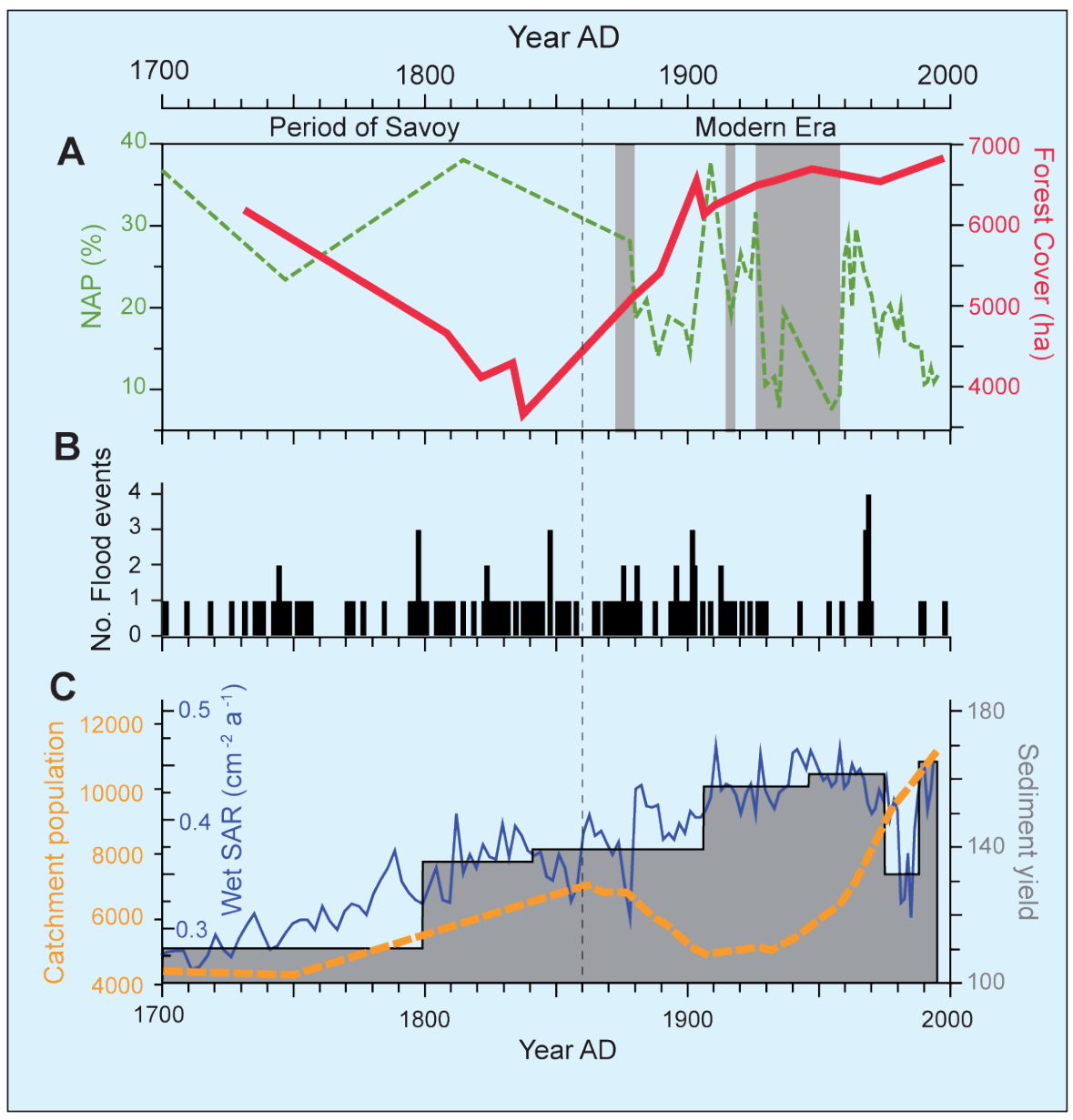

Figure 2: Paleoenvironmental reconstruction and environmental history of the Petit Lac d'Annecy catchment since $A D$ 1700. A) Changes in forested landscape based on non-arboreal pollen percentages (NAP\%, green) and forest inventories (red) for the modern era and the period of Savoy from 1700 to 1860 (shaded areas show rapidly accumulating lake sediments with few pollen). B) Flood record based on documentary sources. C) Human population (yellow), accumulation rate of lake sediments (blue) and estimate of sediment yield (a composite proxy for flooding, slope instability and soil erosion) from the catchment (gray). Note the generally strong relationship between high catchment population and low forest cover, but progressively increasing levels of slope instability and soil erosion up to the mid-20 th century. Rising sediment yields since the 1980 s have now reached the maximum levels seen in the early $20^{\text {th }}$ century.

riod seven main phases of human activity had left their traces in the environmental record. The 1730-1770s and 1840-1860s stood out as two periods of heightened environmental pressures at higher altitudes that led to documented problems in the lowlands, such as flooding, increased erosion and declining soil fertility.

\section{Modeling}

These spatio-temporal interactions were tested through a modeling exercise (Welsh et al., 2009), using the spatially distributed (50 x 50 m grid) hydro-geomorphic process model, CAESAR (Coulthard and Macklin, 2001). Changes in the hydrological and sediment regime of the sub-catchments in the Petit Lac catchment were simulated at hourly time steps over the past 180 years, with forest cover and regional climate as drivers. The results suggested that while minor perturbations in forest cover had partially conditioned the response of the sediment system, the bulk of modeled sediment discharge and particularly the peaks in sediment discharge were controlled by flood duration and magnitude.
These flood parameters were in turn driven by precipitation and snowmelt. Basin geometry and geomorphology of each sub-catchment (Ire and Tamie) were also important in producing differences in the modeled sediment discharge, largely in response to sediment accommodation space and the ability of each system to store and release sediments. The modeled suspended sediment discharge was shown to compare well with lake sediment proxies for detrital sediment accumulation. The results indicated that the model could be used as an exploratory and predictive tool in assessing the likely impact of future changes in climate, meteorology and land use on lake-catchment systems.

\section{Implications for land management}

These contrasting approaches reveal the importance of interactions across different temporal and spatial scales. Different archives of information are biased towards particular scales, and high-precision process models may be essential tools for 
resolving apparent contradictions. For the modern French pre-alpine landscape, there are several significant lessons:

- Forest cover defines the boundary conditions for flood magnitude and slope instability over multi-decadal to centennial timescales, which has been mainly anthropogenically controlled for at least two millennia. In system dynamic terms, land cover represents the set of "slow" processes that control the system's resilience (Dearing, 2008).

- In contrast, the key drivers of short-term flooding and slope instability at commune and sub-catchment levels are linked to specific meteorological events (snowmelt and summer storms) rather than local land-use change, except where there is exceptional land degradation.

- If $21^{\text {st }}$ century winter precipitation increases by $10-20 \%$, the predicted increase in the frequency and magnitude of large flood events in winter and spring could be amplified further as water storage, in the form of snow, is reduced.

- Reducing forest cover and/or increasing frequency/magnitude of flood events render the fluvial system rich in sediment. This not only increases the rate of lateral channel migration, a hazard for farmland and buildings, but also shifts the rivers (mainly through bank erosion) to a more sediment-rich state.

- Anticipating the effects of climate change thus needs to focus on mitigation and adaptation strategies for the likelihood of more frequent extreme meteorological events causing local flooding. However, careful management of land cover across the region will also be needed to raise general levels of flood protection in the winter and spring, and reduce the risk of drought and forest fire in the summer.
Data

Some of the data discussed here can be found at http://www.liv.ac.uk/geography/research_ projects/Levan/index.htm

\section{References}

Coulthard, T.J. and MacKlin, M.G., 2001: How sensitive are river systems to climate and land-use changes? A model-based evaluation, Journal of Quaternary Science, 16: 347-351.

Crook, D.S., Siddle, D.J., Jones, R.T., Dearing, J.A., Foster, G.C. and Thompson, R., 2002: Forestry and flooding in the Annecy Petit Lac Basin, 1730-2000, Environment and History, 8(4): 403-428.

Crook, D.S., Siddle, D.J., Dearing, J.A. and Thompson, R., 2004: Human Impact on the Environment in the Annecy Petit Lac catchment Haute-Savoie: A documentary approach, Environment and History, 10(3): 247-284.

Foster, G., e, et al, 2003: Meteorological and land use controls on geomorphic and fluvial processes in the pre-Alpine environment: an integrated lake-catchment study at the Petit Lac d'Annecy, Hydrological Processes, 17(16): 3287-3305.

Welsh, K.E., Dearing, J.A., Chiverrell, R.C. and Coulthard, T.J., 2009: Testing a cellular modelling approach to simulating late-Holocene sediment and water transfer from catchment to lake in the French Alps since 1826, The Holocene, 19: 785-798.

For full references please consult:

http://www.pages-igbp.org/products/newsletters/ref2011_2.pdf

\title{
Past land use and soil erosion processes in central Europe
}

\author{
Markus Dotterweich ${ }^{1}$ and Stefan Dreibrodt ${ }^{2}$ \\ ${ }^{1}$ Institute of Geography, University of Mainz, Germany; mail@markus-dotterweich.de \\ ${ }^{2}$ Institute for Ecosystem Research, University of Kiel, Germany
}

\section{0 years of land use and soil erosion data provide an insight into modern links between human activities and the environment.}

\section{Agricultural development and geomorphology}

The development of natural and socioecologically adapted agroecosystems, which have the capacity to ease demand on food and resources and mitigate climate change, is a major challenge. Looking at past land-use systems and their socio-economic history increases our understanding of slow processes and low-frequency events. These underlying processes appear to be key in assessing whether modern land-use systems will lead to sustainability or collapse.

In central Europe, phases of agricultural expansion and regression occurred with land clearance and reforestation back to the onset of agriculture, around 7500 years ago. Under natural conditions (except for short phases of severe climate deterioration in the early Holocene), the sheltering cover of vegetation and soil development largely mitigated geomorphic processes, resulting in a stable dynamic equilibrium (Dotterweich, 2008). With the clearing of forests, the natural water and matter fluxes changed into anthropogenically driven systems with greatly accelerated processes and higher vulnerability to soil erosion. Repeated or extreme events forced by climate change may have af- fected the fertility of the land to an extent that it could no longer be cultivated. On a local- to regional scale, this may occur surprisingly rapidly, especially in strong single events. As the system develops, two outcomes may occur: a) Driving forces may progress slowly, causing gradual and predictable degradation, or b) Exceptional

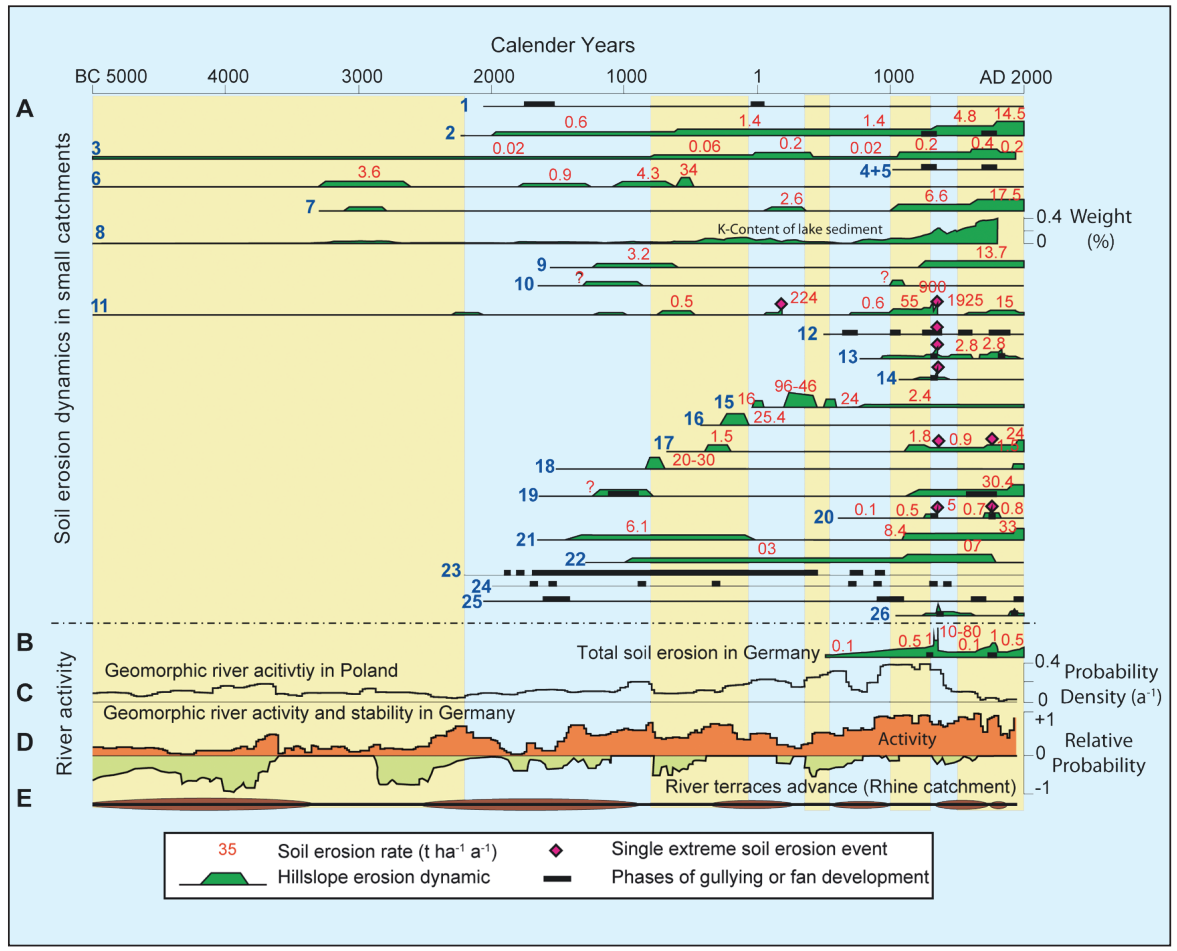

Figure 1: Dynamics of soil erosion in small catchments $(\boldsymbol{A})$ and river activity $(\boldsymbol{B}, \boldsymbol{C}, \boldsymbol{D}, \boldsymbol{E})$ in central Europe since the beginning of agriculture, based on studies by different authors. Blue numbers correlate to site names, type of geoarchive and references given in supplementary material (www.pages-igbp.org/products/newsletters/ref2011_2. pdf). Yellow shading represents cultural epochs (Figure modified from Dotterweich, 2008). 